\title{
O ANO DA CATÁBASE DE RICARDO REIS \\ UM TOPOS HOMÉRICO NO ROMANCE DE JOSÉ SARAMAGO
}

\author{
THE YEAR OF THE KATABASIS OF RICARDO REIS \\ AN HOMERIAN TOPOI IN JOSÉ SARAMAGO'S NOVEL
}

\section{EL AÑO DE LA CATÁBASIS DE RICARDO REIS. \\ UN TOPOS HOMÉRICO EN LA NOVELA DE JOSÉ SARAMAGO}

\author{
Luís Ricardo Duarte \\ Jornal de Letras, Artes e Ideias
}

\begin{abstract}
In José Saramago's work there are frequent allusions to Classical themes, arising from his thorough knowledge of the ancient works, but also influenced by the "popular repertoire" Saramago liked so much. However, The Year of the Death of Ricardo Reis is more than a mere quote. The reader will witness a conscious or unconscious reworking of one of the most famous Greek topoi, the Homerian Katabasis, a descent into Hell. In 1936 Lisbon, Ricardo Reis, like Ulysses, discovers the "truth".
\end{abstract}

Key words: José Saramago, Ricardo Reis, Classical themes, Katabasis, Homer.

\section{RESUMO}

Na obra de José Saramago, são frequentes as referências e glosas a temas clássicos, por conhecimento aprofundado, mas também por recurso ao «tesouro popular» que o escritor tanto apreciava. Mas em O Ano da Morte de Ricardo Reis encontramos mais do que uma mera citação. Acreditamos estar perante uma reconfiguração, consciente ou inconsciente, de 
um dos topos gregos mais famosos, a catábase homérica, a descida aos infernos. Na Lisboa de 1936, Ricardo Reis, como Ulisses, vem saber da verdade.

Palavras-chave: José Saramago, Ricardo Reis, Temas clássicos, Catábase, Homero.

\section{RESUMEN}

En la obra de José Saramago son frecuentes las referencias y glosas de temas clásicos. Por un lado, por su profundo conocimiento, pero también por la voluntad del escritor de recurrir al «tesoro populan» que tanto apreciaba. Sin embargo, en El año de la muerte de Ricardo Reis encontramos más que una mera cita. Creemos estar ante una reconfiguración, consciente o inconsciente, de uno de los tópicos griegos más famosos, la catábasis homérica, la bajada a los infiernos. En la Lisboa de 1936, Ricardo Reis, al igual que Ulises, conocerá la verdad.

Palabras clave: José Saramago, Ricardo Reis, Temas clásicos, Catábase, Homero.

Fecha de recepción: 18 de noviembre de 2019.

Fecha de aceptación: 11 de diciembre de 2019.

Cómo citar: Duarte, Luís Ricardo (2019): «O ano da catábase de Ricardo Reis. Um topo homérico no romance de José Saramago», en Actio Nova: Revista de Teoría de la Literatura y Literatura Comparada, Monográfico 3: 81-94.

DOI: https://doi.org/10.15366/actionova2019.m3.006 
«Quantas vezes será preciso dizer-lhe que se regressei foi por sua causa» In O Ano da Morte de Ricardo Reis

Descobrir temas clássicos na obra de José Saramago não exige uma leitura muito atenta. Nas crónicas, contos, poemas e romances - em qualquer texto salta à vista o seu conhecimento (vasto e aprofundado) da antiguidade clássica. Ao correr das páginas, são glosados ou reinventados mitos, episódios e frases célebres. Umas vezes por estar o autor em sintonia ideológica e estética com esse legado. Noutras por representar esse legado parte da sabedoria ou «tesouro popular» a que o escritor sempre deitou a mão (Seixo, 1987: 48).

Não é nosso propósito circum-navegar a presença clássica na obra de José Saramago, tarefa fascinante que exigiria outro tempo e outro espaço. Apenas pretendemos, com este ensaio, reforçar essa ligação ao defender que o escritor reconfigurou, consciente ou inconscientemente, um topos grego por excelência num dos seus romances mais celebrados ${ }^{1}$. $\mathrm{Na}$ leitura que propomos, $\mathrm{O}$ ano da morte de Ricardo Reis afigura-se um exemplo contemporâneo, adulterado mas ainda assim fidedigno, da catábase clássica, sobretudo a homérica, aquela que ainda não tem, como terá a partir de Virgílio e mais tarde de Dante, um cunho religioso ${ }^{2}$.

2.

Esta leitura de $O$ ano da morte de Ricardo Reis é inspirada no artigo de Maria Carvalhão Buescu sobre o último capítulo de Os Maias, justamente apresentado como uma catábase. Afirma a ensaísta:

\footnotetext{
${ }^{1} \mathrm{Na}$ verdade, a ideia inicial deste trabalho era identificar ecos de Horácio no narrador de $O$ ano da morte de Ricardo Reis, tentando imaginar uma corrente literária a começar no poeta romano, a passar pelo heterónimo pessoano e a acabar no narrador de José Saramago. Um tema que ainda nos interessa mas que foi suplantado pelo que nos pareceu uma hipótese mais estimulante, concreta e definível do que a primeira.

${ }^{2}$ «A descida de Eneias, porém, já é descrita com uma tonalidade religiosa que não encontramos na catábase homérica, pois é nítida a influência de doutrinas órficas, como se vê pelo aparecimento do "ramo de ouro"». E mais à frente, sobre Dante: «A alegoria torna-se abertamente cristianizada e espiritualizada no sentido cristão, é a salvação do homem na sua passagem pela terra, que está em jogo, e o caminho para o paraíso está coberto de espinhos» (Fernandes, 1993: 348 e ss).
} 
Entrecruzam-se, na estrutura mítico-simbólica que subjaz a Os Maias, dois grandes temas modelos. Por um lado, a catarse purificatória, a que a ocultação e a viagem e, finalmente, a epifania constituem um modo de acesso ou um meio de consecução. Por outro, a prova final e máxima, constituída pela catábase, descida aos infernos, caminho em sentido inverso, capaz de anular o tempo e o acontecimento, como se fosse dado enrolar o fio desenrolado pela Parca e regressar ao ponto de partida (Buescu, 1985: 108).

Para Carlos da Maia o regresso ao Ramalhete, palco de todos os dramas familiares, apresenta-se assim como uma viagem infernal, do qual sairá «outro», ele mesmo «renascido»: «Essa 'descida' constitui uma rutura, o rompimento definitivo com o passado, marcado pela transgressão. Sinaliza, em última análise, o descensus de utero, a vida para o renascimento. Carlos atinge o espaço exterior. Atrás de si ficou Ele Mesmo porque agora é já Outro» (Buescu, 1985: 117).

Como a própria Maria Leonor Carvalhão Buescu adverte, trata-se, obviamente, de uma «leitura aberta», fundada no «problema da mitologização inconsciente pelo criador literário», que, no entanto, ilumina o «sentido profundo» do último capítulo da obra-prima de Eça de Queirós (Buescu, 1985: 105).

Avançamos com esta proposta de interpretação conhecendo as reservas levantadas por Rosado Fernandes ao artigo de Carvalhão Buescu, em particular as que dizem respeito às diferenças entre catábase e lugar amaldiçoado pelo passado.

Há efetivamente sinais de morte em todo o ambiente da casa, e por isso o regresso é entendido, não literalmente, mas metaforicamente e psiquicamente dentro do mundo do imaginário, uma catábase, o que constitui interpretação atraente, se não se levantassem vários óbices, que vão desde o vitium retórico do kakózelon, em sentido lato, até ao desconhecimento da história literária da época romântica, que nos oferece outros parâmetros para julgar esta história queirosiana», sublinha o investigador (Fernandes, 1993: 355).

Acreditamos, ainda, ter percebido o sentido dos argumentos do classicista quando afirma:

Uma identificação não deve ser aceite só por extrapolação, uma vez que se necessita de um pouco mais do que unicamente de signos exteriores para que se processe uma descida aos infernos, o que quer dizer que descida aos infernos é mesmo o que isso significa, a menos que queiramos entrar numa interpretação simbólica do tipo das que já fizeram os escoliastas homéricos ou o nosso compatriota Faria de Sousa nos seus comentários aos Lusiadas (Fernandes, 1993: $358)$. 
A análise do texto, porém, parece confirmar a hipótese, que acima de tudo é um contributo para um melhor entendimento do romance, que não pode esquecer o que outras interpretações já sublinharam: a importância da intertextualidade e da revisitação da História. É também uma hipótese que ganha sentido se se tiver em conta o uso da paródia feito por José Saramago nos seus romances. Paródia essa que, com o Post-Modernismo, assumiu novas configurações, mais próximas da «auto-reflexidade» do que do «intuito risível». Como sintetiza Ana Paula Arnaut:

Deixando de lado a definição demasiado restritiva que tem sido cristalizada em vários dicionários, e que liga obrigatoriamente o conceito a um intuito risível, ridicularizador, deve passar a aceitar-se que paródia - uma das formas mais importantes da moderna auto-reflexividade e discurso inter-artístico - é uma forma de imitação caracterizada por uma inversão irónica, nem sempre às custas do texto parodiado. Noutra formulação, também proposta por Linda Hutcheon, paródia é repetição com distância crítica, que marca a diferença em vez da semelhança. Nesse sentido, não se trata de uma questão de imitação nostálgica de modelos passados: é uma confrontação, uma recodificação moderna que estabelece a diferença no coração da semelhança e que não exige que a crítica esteja presente na forma de riso ridicularizador (Arnaut, 2008: 27).

Ainda segundo Ana Paula Arnaut, em José Saramago «o efeito de afastamento e de distanciamento crítico permite transformar o exercício de imitação de um texto por outro texto numa verdadeira arma ideológica» (Arnaut, 2008: 208).

Com o inferno do Estado Novo e da Guerra Civil Espanhola como pano de fundo, ideologia, na verdade, é o que não falta em $O$ ano da morte de Ricardo Reis.

3.

A par da interpretação simbólica proposta por Maria Carvalhão Buescu, os paralelismos entre o texto saramaguiano e o épico homérico, que correspondem às exigências de Rosado Fernandes, foram igualmente preponderantes para a nossa leitura.

À semelhança da catábase de Ulisses, relatada no canto XI da Odisseia, a de Ricardo Reis também tem início debaixo de um céu cerrado. Segundo a mitologia pessoana, este heterónimo nasceu no Porto, em 1887, onde exerceu medicina. Enquanto poeta foi discípulo de Alberto Caeiro e cultor das odes clássicas, que reinventou através de um «neoclassicismo 
científico» (Silva, 2003: 278). Dele disse Fernando Pessoa, numa das suas frases lapidares, ser «Horácio grego que escreve em português» (Silva, 2003: 229).

Facto marcante na vida imaginária de Ricardo Reis é a decisão de partir para o Brasil, em 1919. Num país recém-convertido à República, que alternativa tinha um monárquico? Além disso, quatro anos antes, em 1915, tinha morrido o seu mestre, Alberto Caeiro. O que fazer num país onde se sentia apátrida? Partiu sem bilhete de regresso. Cruzou o Atlântico e dele nada mais se soube. Só a ficção de José Saramago foi capaz de o trazer de volta e interromper o exílio autoimposto. «Ricardo Reis regressou a Portugal depois da morte de Fernando Pessoa», anunciou o escritor na contracapa do romance.

À semelhança de Ulisses, dizíamos, Ricardo Reis inicia a sua catábase sob um céu cerrado. Também vem de barco. Não uma «nau veloz», como o herói grego, mas no Highland Brigade que, rumo a Londres, faz escala na capital portuguesa. Nas «margens do Oceano de correntes profundas», o filho de Laertes encontra uma terra - a dos Cimérios «debaixo de nevoeiro e de nuvens», onde «nunca os contempla o sol resplandecente com seus raios» (Homero, 2003: Canto XI, vv. 13/15). Em Lisboa, o cenário com que Ricardo Reis se depara é idêntico. Do vapor inglês nada se vê:

Em dias de amena meteorologia, o Highland Brigade é jardim de crianças e paraíso de velhos, porém não hoje, que está chovendo e não iremos ter outra tarde. Por trás dos vidros embaciados de sal, os meninos espreitam a cidade cinzenta, urbe rasa sobre colinas, como se só de casas térreas construída, por acaso além um zimbório alto, uma empena mais esforçada, um vulto que parece ruína de castelo, salvo se tudo isto é ilusão, quimera, miragem criada pela movediça cortina das águas que descem do céu fechado (Saramago, 2011: 10).

É «parda neblina» que tudo «obscurece» (Saramago, 2011: 11), «maldito inverno» que destrói campos férteis que tanta falta fazem (Saramago, 2011: 12). Estação infindável, descobrirá Ricardo Reis, que rima com os tempos sombrios que se abateram sobre o país:

Este contínuo mau tempo de há meses, ou anos, que antes não estávamos nós cá, os vendavais, os dilúvios, as cheias, já se falou o suficiente da gente desta nação para reconhecermos nas penas dela a explicação da irregularidade dos meteoros (Saramago, 2011: 258). 
Mas por que motivo regressou Ricardo Reis a Lisboa, transportado pela poderosa imaginação de José Saramago?

Na sua matriz clássica esclarece Rosado Fernandes em artigo já citado:

O mundo subterrâneo, com todo o sortilégio que lhe confere o misterioso desconhecido, com a força ctónica que lhe é particular, apresenta-se aos antigos como um reino onde a verdade pode ser encontrada ou, pelo menos, ouvida, porque as almas dos que desapareceram da terra a podem contar mais livremente, testemunhas que foram das muitas peripécias já lendárias por que passaram no mundo dos vivos (Fernandes, 1993: 349).

Segundo o tradutor da Arte Poética de Horácio,

quando os mortais, heróis (semimortais) ou imortais descem em catábase aos infernos, fazem-no quase sempre para averiguarem o que de pouco claro se lhes afigura na vida terrena, ou para cumprirem qualquer missão de importância (Hércules), em geral em favor de qualquer pessoa ou comunidade humana» (Fernandes, 1993: 349).

Investido de importante missão não vem Ricardo Reis, de novo em Lisboa, passados 16 anos. Mas tanto em relação ao seu amigo Fernando Pessoa, quanto ao espetáculo do mundo (aquele que, segundo a ode, só os sábios sabem contemplar), traz consigo muito por esclarecer.

$\mathrm{Na}$ sua descida, Ulisses tem um objetivo claro. «Foi a necessidade que me trouxe ao Hades» (Homero, 2003: Canto XI, vv. 163/165), diz a quem lhe pergunta. Veio saber do «doce regresso»a Ítaca, que Posídon fez difícil por o herói de Tróia ter cegado o seu filho Polifemo. Quem lhe indica o caminho é Tirésias, dizendo a «verdade» depois de beber do «negro sangue».

Certo é que, uma vez no Hades, Ulisses não se contenta em saber do seu destino. Quer conhecer ainda a sorte dos seus familiares e amigos, companheiros de dez anos de guerra em Tróia. «Diz-me agora tu com verdade e sem rodeios:/ como te venceu o destino da morte de prolongada tristeza?», pergunta à mãe (Homero, 2003: Canto XI, vv. 170/171). O mesmo pergunta a Agamémnon e a outros heróis. A sua curiosidade não tem limites.

Nos dias iniciais em Lisboa, embora perdido e confuso, Ricardo Reis também se deixa guiar pela mesma curiosidade. Quererá, em primeiro lugar, saber como morreu Fernando Pessoa, que última imagem deixou no mundo, ler os obituários escritos depois desse triste 30 de Novembro de 1935. Segue rua fora, informa o narrador, vai aos jornais, 
«vai aonde sempre terá de ir quem das coisas do mundo passado quiser saber» (Saramago, 2011: 42). Sem ter a quem perguntar e sem ter ainda encontrado o próprio poeta, é a sua única alternativa. Também irá ao cemitério e neste passo fica claro o propósito da sua viagem. Lê-se no romance:

A morte de Fernando Pessoa parecera-lhe forte razão para atravessar o Atlântico depois de dezasseis anos de ausência, deixar-se ficar por cá, vivendo da medicina, escrevendo alguns versos, envelhecendo, ocupando, duma certa maneira, o lugar daquele que morrera, mesmo que ninguém se apercebesse da substituição (Saramago, 2011: 453).

Mais adiante, já perante a figura de Fernando Pessoa, Ricardo Reis reforça a ideia: «Quantas vezes será preciso dizer-lhe que se regressei foi por sua causa» (Saramago, 2011: 208). Como Orfeu por Eurídice. Não por amor, mas por cumplicidade.

Ricardo Reis desceu ao inferno luso porque tem dúvidas e José Saramago lhe garante que os mortos podem contar mais livremente a verdade que testemunharam, como acontece com Ulisses no Hades. Várias passagens ao longo do livro atestam essa capacidade, fortalecendo o paralelismo com o arquétipo homérico. «Pelo que vou aprendendo os mortos ainda são piores que os velhos, se lhes dá para falar perdem o tento na língua», diz Fernando Pessoa a Ricardo Reis, que responde: «Tem razão, se calhar é o desespero de não terem dito o que queriam enquanto foi tempo de lhes aproveitar» (Saramago, 2011: 249).

Mais direta é a afirmação que, páginas à frente, surge na boca de Fernando Pessoa: «O morto tem a vantagem de já ter sido vivo, conhece todas as coisas deste mundo e desse mundo, mas os vivos são incapazes de aprender a coisa fundamental e tirar proveito dela» (Saramago, 2011: 381). Em suma: «Quando se está morto, sabe-se tudo, é uma das vantagens», garante Fernando Pessoa (Saramago, 2011: 109). Por isso «quando se chega a morto, vê-se a vida de outra maneira» (Saramago, 2011: 466).

5.

Não é isenta de perigos a descida aos infernos. A mãe de Ulisses é a primeira a avisar o herói grego. «Meu filho, como vieste ter sob a escuridão nebulosa, tu que estás vivo? É difícil para os vivos contemplar tais coisas» (Homero, 2003: Canto XI, vv. 155/156), dizlhe assim que o reconhece. Fernando Pessoa terá o mesmo cuidado com Ricardo Reis. «Não 
é bom para os mortos habituarem-se a viver com os vivos, e também não seria bom para os vivos atravancarem-se de mortos» (Saramago, 2011: 466).

O poeta também lembra ao amigo o muito que está vedado do lado de lá da morte: «Há coisas deste lado que não nos são permitidas» (Saramago, 2011: 505). Aqui não se distancia da mãe de Ulisses. «É a lei que está estabelecida para os mortais, quando morrem. Pois os músculos já não seguram a carne e os ossos, mas vence-os a força dominadora do fogo ardente, quando a vida abandona os brancos ossos e a alma, como um sonho, batendo as asas se evola», explica Anticleia (Homero, 2003: Canto XI, vv. 210/222).

Para Ricardo Reis não serão só os abraços, serão a capacidade de ler, vedada aos mortos, e o esquecimento, o mesmo que atinge os heróis da guerra de Tróia quando afastados do «negro sangue». A esse propósito, lembra Pessoa: «Eu avisei-o logo no primeiro dia, com o passar do tempo vou-me esquecendo, ainda agora, ali no calhariz, tive de puxar pela memória» (Saramago, 2011: 461).

Através da engenhosa prosa de José Saramago, o autor de Mensagem diz mais qualquer coisa que faz lembrar a Odisseia: «Estranha coisa é a morte, mais estranho ainda, olhando-a do lado em que estou, é verificar que não há duas mortes iguais, estar morto não é o mesmo para todos os mortos, há casos em que transportamos para cá todos os fardos da vida» (Saramago, 2011: 388). Que melhor descrição para o espanto de Ulisses perante o afastamento e o silêncio de Ájax, ainda ressabiado por causa da disputa das armas de Aquiles?

Sendo $O$ ano da morte de Ricardo Reis, efetivamente, uma viagem, os paralelismos com a catábase são suficientes para podermos continuar a sustentar a nossa proposta. Mas falta o mais importante: a descrição do inferno.

6.

Ao se dirigir a Ulisses, Anticleia descreve o inferno como uma terra cheia de «grandes rios e torrentes medonhas»(Homero, 2003: Canto XI, vv. 157). As futuras recriações da catábase homérica vão explorar muito esta componente descritiva. Também a encontramos no romance de José Saramago. Deambulando por Lisboa, Ricardo Reis apercebe-se da dura realidade do Estado Novo, agravada pelo conflito que do outro lado da fronteira se trava entre republicanos e nacionalistas nos inícios da Guerra Civil Espanhola.

É a componente ideológica que a generalidade dos estudos sobre este romance 
destaca. «A espessura do quotidiano é refeita com escrupulosa exatidão. As ruas, as praças, os itinerários de Lisboa, a cor e o volume das pedras da calçada, os gestos das pessoas, tudo é minuciosamente descrito como uma gloriosa proclamação da entidade do objeto», sublinha Luís de Sousa Rebelo (1985: 146). E acrescenta: «O próprio desenvolvimento da narrativa é uma viagem através de formas e aparências, que despertam múltiplas interrogações, e inclui no seu itinerário a inevitável violência dos grandes sismos sociais em que é pródiga a década de 30» (Rebelo, 1985: 146).

Do Brasil, Regina Zilberman aponta no mesmo sentido:

Dos dois lados do oceano Atlântico, o fascismo afirmava-se, mesmo porque as possíveis forças de esquerda estavam manietadas pela emergência do totalitarismo na União Soviética, de que os expurgos, comandados por Joseph Estaline, eram o sinal mais evidente. É tendo por pano de fundo tais acontecimentos que se constrói o enredo de $O$ ano da morte de Ricardo Reis (Zilberman, 2011:137).

A lusitanista dá como exemplo da forte carga ideológica da obra a coincidência entre a revolta dos marinheiros, onde morrerá o irmão de Lídia, amante de Ricardo Reis, e a morte concreta deste: «O ano da morte de Ricardo Reis é também o da morte de Portugal e da Europa democrática» (Zilberman, 2011:139).

«Dá-se especial realce [neste romance] à atmosfera político-social do País, ao ambiente lisboeta, aos acontecimentos históricos mais importantes» (Seixo, 1987: 47), diz, na mesma linha, Maria Alzira Seixo, que chama ainda a atenção a necessidade de se estudar mais a fundo o «tratamento ideológico» (Seixo, 1987: 48) deste e de outros textos do autor.

Em estudo alongado sobre o escritor, Ana Paula Arnaut também se refere a esta ideologia, que capta os «cinzentos tempos da ditadura salazarista» (Arnaut, 2008: 26). Como momentos essenciais desse retrato negro, a ensaísta aponta três episódios:

O relato do encontro entre Ricardo Reis e a PIDE ou, num outro nível, a desmontagem da confraria mercantil e da máquina publicitária em que o regime transformou Fátima e o seu milagre. Recordemos, ainda, como bem assinala Teresa Cristina Cerdeira da Silva, que alguns dos diálogos mantidos entre esta personagem e Fernando Pessoa criam oportunidade para comentários cáusticos e dessacralizadores: sobre regimes totalitários; sobre a religião, provavelmente regime não menos totalitário que os políticos; sobre diversas e múltiplas injustiças e atrocidades que, sob muitas máscaras, sempre se exerceram sobre os mais fracos» (Arnaut, 2008: 27).

Tudo isto vê Ricardo Reis, o inferno de Lisboa, o sufoco de uma ditadura que 
cresce, uma guerra que se aproxima. E vê com a mesma força (poética) e intensidade (narrativa) com que Ulisses vê Antíope, Alcmena, Mégara, Épicas, Clóris, Leda, Fedra e outras almas condenadas. Até o Estado Novo tem os seus cães de fila, como o Hades homérico tem Cérbero: o inspector Victor, sempre de vigia. Felizmente, o seu cheiro a cebola sente-se à distância. Ricardo Reis saberá proteger-se.

Estamos perante um inferno simbólico, metafórico, literário? Sem dúvida - mas não será também assim o de Homero?

7.

Por que regressou Ricardo Reis a Lisboa, transportado pela poderosa imaginação de José Saramago? A dúvida permanece. Para se descobrir? «Talvez que eu tenha voltado a Portugal para saber quem sou», desabafa a certa altura a Fernando Pessoa (Saramago, 2011: 159). Provavelmente, sabe que «afinal tudo é difuso» (Saramago, 2011: 40) e que o tempo guarda de nós muito pouco. Quis conhecer a morte para, em vida, saber o que o espera? Receio do esquecimento? Talvez. «É bem verdade que não basta gravar o nome numa pedra, a pedra fica, sim senhores, salvou-se, mas o nome, se todos os dias o não forem ler, apagase, esquece, não está cá», avisa o narrador (Saramago, 2011: 79), diante da estátua de Camões. O que permanece? «Há-de o homem esforçar-se sempre, para que esse seu nome de homem mereça, mas é menos senhor da sua pessoa e destino do que julga, o tempo, não o seu, o fará crescer ou apagar, por outros merecimentos algumas vezes, ou diferentemente julgados» (Saramago, 2011: 93).

Como Aquiles, frente às muralhas de Tróia, também este Ricardo Reis de José Saramago se apercebe da «volubilidade dos homens, tão ociosos do pouco tempo que têm para viver, sempre a queixarem-se de serem curtas as vidas, deixando à só memória um branco som de espuma» (Saramago, 2011: 101). No inferno de Lisboa, descobre a verdade da vida. A ditadura do esquecimento.

Que fazer, então? Um só caminho se abre a Ricardo Reis - obviamente simbólico, metafórico, literário -, o proposto pelo romance de Saramago: acompanhar Fernando Pessoa para lá das portas do inferno, rumo à eternidade, na certeza de que: 
Dos versos em que fico,

Nem temo o influxo inúmero futuro

Dos tempos e do olvido;

Que a mente, quando, fixa, em si contempla

Os reflexos do mundo,

Deles se plasma torna, e à arte o mundo

Cria, que não a mente.

Assim na placa o externo instante grava

Seu ser, durando nela ${ }^{3}$.

3 Ode de Ricardo Reis. 


\section{BIBLIOGRAFÍA}

Arnaut, Ana Paula (2008): José Saramago, Lisboa, Edições 70.

Buescu, Maria Leonor Carvalhão (1985): O regresso ao Ramalhete, in Ensaios de Literatura Portuguesa, Lisboa, Editorial Presença.

Fernandes, Raul Miguel Rosado (1993): Catábase ou descida aos infernos. Alguns exemplos literários, in Hvmanitas, vol. XLV.

Homero (2003): Odisseia, tradução de Frederico Lourenço, Lisboa, Cotovia, 2003, Canto XI, vv. $13 / 15$.

Rebelo, Luís de Sousa (1985): José Saramago: O ano da morte de Ricardo Reis, in Revista Colóquio/Letras, 88, Nov. 1985.

Saramago, José (2011): O ano da morte de Ricardo Reis, 20. a edição, Lisboa, Editorial Caminho, [1984].

Seixo, Maria Alzira (1987): O essencial sobre José Saramago, Lisboa, INCM.

Silva, Manuela Parreira da (2003): Ricardo Reis. Prosa, Lisboa, Assírio \& Alvim.

Zilberman, Regina (2011): O ano da morte de Ricardo Reis - História e não-História, in Revista Ipotesi, v. 15, n. 1, jan./jun. 2011. 
SOBRE EL AUTOR

\section{Luís Ricardo Duarte}

Luís Ricardo Duarte é jornalista do Jornal de Letras, Artes e Ideias desde 2003. Nasceu em Lisboa, em 1977, e cresceu em Setúbal. Na Faculdade de Letras da Universidade de Lisboa licenciou-se em História da Arte, onde foi director do jornal Os Fazedores de Letras. Fez formação complementar em Literatura, ainda na FLUL, e em Jornalismo, no CENJOR. Na Universidade de Coimbra, conluiu a parte curricular do Mestrado em Estudos Clássicos. Lê para escrever e escreve para ler.

Contact information: correo electrónico:1ricardoduarte@gmail.com 